\title{
Design and fabrication of single grain TFTs and lateral photodiodes for low dose X-ray detection
}

\author{
A. Arslan, R. Ishihara, J. Derakhshandeh, C.I.M. Beenakker \\ Delft Institute of Microsystems and Nanoelectronics (DIMES), Delft University of Technology, \\ P.O. Box 5053, 2600 GB Delft, the Netherlands \\ E-mail: a.arslan@tudelft.nl
}

\begin{abstract}
Design, fabrication and measurement results of single grain (SG) lateral PIN photodiodes and SG thin film transistors (TFT) are reported in this paper. Devices were developed to be used in indirect X-ray image sensor pixel design. We have controlled position of $6 \mu \mathrm{m} \times 6 \mu \mathrm{m}$ silicon grains with excimer-laser crystallization of a-Si film. Lateral PIN photodiode (PD) arrays were designed inside the single grain with $1 \mu \mathrm{m}, 1.5 \mu \mathrm{m}$ and $2 \mu \mathrm{m}$ intrinsic region length and 4 $\mu \mathrm{m}$ width. The gate length and the width of the fabricated TFTs are $1.5 \mu \mathrm{m}$ and $4 \mu \mathrm{m}$, respectively. Devices were fabricated using a-Si, SOI and crystalline silicon layers and electrical measurement results were compared. $100 \mu \mathrm{m} \times 100$ $\mu \mathrm{m}$ sizes SG-photodiodes have dark and saturation currents on the order of $0.1 \mathrm{nA}$ and $10 \mathrm{nA}$ resulting in a light sensitivity of 200 with an exposure of white light. Fabricated NMOS and PMOS TFTs inside the grains have field effect mobility of $526 \mathrm{~cm}^{2} / \mathrm{Vs}$ and $253 \mathrm{~cm}^{2} / \mathrm{Vs}$, respectively.
\end{abstract}

Keywords: X-ray, thin-film-transistor (TFT), single grain, large area detection, image sensor, $\mu$-Czochralski process

\section{INTRODUCTION}

Patients are exposed to a relatively high amount of X-ray radiation during medical diagnostics and treatment which already carries a risk as a consequence of radiation accumulation in the body. Therefore, to decrease the dose without losing the image quality, X-ray detector performance has to be improved. Digital X-ray radiography detectors are currently using a-Si thin-film-transistors (TFTs) which can be fabricated with lower process temperature compared to IC technology and hence permit use of large area glass substrates. However, due to the amorphous nature, mobility is very low $\left(1 \mathrm{~cm}^{2} / \mathrm{Vs}\right)$ resulting in an image lag problem. Poly-Si TFTs will improve mobility and thereby enables higher resolution, but due to existence of random grain boundaries [1], sensitivity is low.

Motivation of this paper is to develop an indirect X-ray detector [2], which employs a scintillator to convert X-ray to visible light and light sensitive 2D-location controlled silicon islands for photodiode array and readout electronics, as shown in Figure 1. A low-temperature process, based on the $\mu$-Czochralski technique with excimer-laser crystallization of a-Si film, has been developed in TU Delft and used to control the positions of the islands. The proposed X-ray image sensor is a solution to the lag problem and frequency limitation of a-Si TFT via high mobility [3] while achieving a detection area for chest radiography without the tiling process which causes data lost at the connection of the detector arrays.

In this paper, first the $\mu$-Czochralski technique is explained and then the SG- TFT and SG-PD designs are presented. SGPDs were fabricated using $1 \mu \mathrm{m}$ thick crystallized Si layer to increase the sensitivity of the silicon layer for long wavelengths $(>400 \mathrm{~nm})$. For comparison, we fabricated same PD designs using SOI and a-Si deposited wafers, as well. SG-PDs were fabricated in three different sizes to determine the pixel size of the image sensor. Measurement results show that, SG- PD can be substitute of single crystalline PDs with its high sensitivity and low dark current. SG- TFTs were fabricated with $250 \mathrm{~nm}$ thick crystallized silicon layer with $1.5 \mu \mathrm{m}$ gate length. Transfer characteristics of SGNMOS and SG- PMOS TFTs are demonstrated.

Medical Imaging 2011: Physics of Medical Imaging, edited by Norbert J. Pelc, Ehsan Samei, Robert M. Nishikawa, Proc. of SPIE Vol. 7961, 79614N · @ 2011 SPIE · CCC code: 1605-7422/11/\$18 · doi: 10.1117/12.877959 


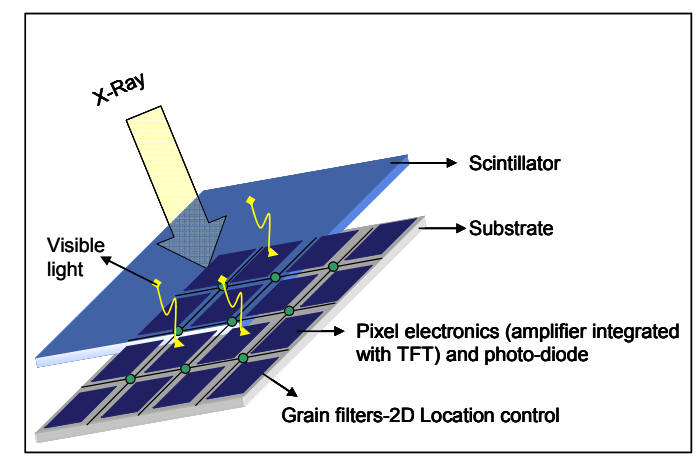

Figure 1. Scheme of the indirect-detection X-ray image sensor with single grain technique.

\section{LOCATION CONTROLLED CRYSTALLIZATION and FABRICATION of SG-PHOTODIODES and SG-TFTs}

The $\mu$-Czochralski process is employed to fabricate 2D- location controlled Si grains. Process flow started with oxidation of 4-inch Si-wafer. $1 \mu \mathrm{m} \times 1 \mu \mathrm{m}$ size cavities were patterned in a $750 \mu \mathrm{m}$ thick $\mathrm{SiO}_{2}$ layer. The cavity diameter was reduced to $100 \mathrm{~nm}$ with depositing $855 \mathrm{~nm}$ tetra ethyl ortho silicate (TEOS) using plasma-enhanced chemical vapor deposition (PECVD) at $350{ }^{\circ} \mathrm{C}$. After defining the cavities which later serve as the grain filter, a $250 \mathrm{~nm}$ or $1 \mu \mathrm{m}$ thick amorphous silicon (a-Si) was deposited by low-pressure plasma chemical vapor deposition (LPCVD) on different wafers. The wafers with $250 \mathrm{~nm}$ and $1 \mu \mathrm{m}$ thick a-Si layer were shot with $1400 \mathrm{~mJ} / \mathrm{cm}^{2}$ and $3400 \mathrm{~mJ} / \mathrm{cm}^{2}$ excimer laser fluence, respectively, at $450{ }^{\circ} \mathrm{C}$. The corresponding pulse durations were $25 \mathrm{~ns}$ and $250 \mathrm{~ns}$. Crystallization starts from the grain filter and hillocks are formed at the locations where adjacent grains collide. Grain size is defined by the pitch of the grain filters and laser energy. SEM image of $1 \mu \mathrm{m}$ thick crystallized layer is illustrated in Figure 2. $6 \mu \mathrm{m}$ x $6 \mu \mathrm{m}$ size square shape grains have been successfully obtained by the location-controlled single grain technique.

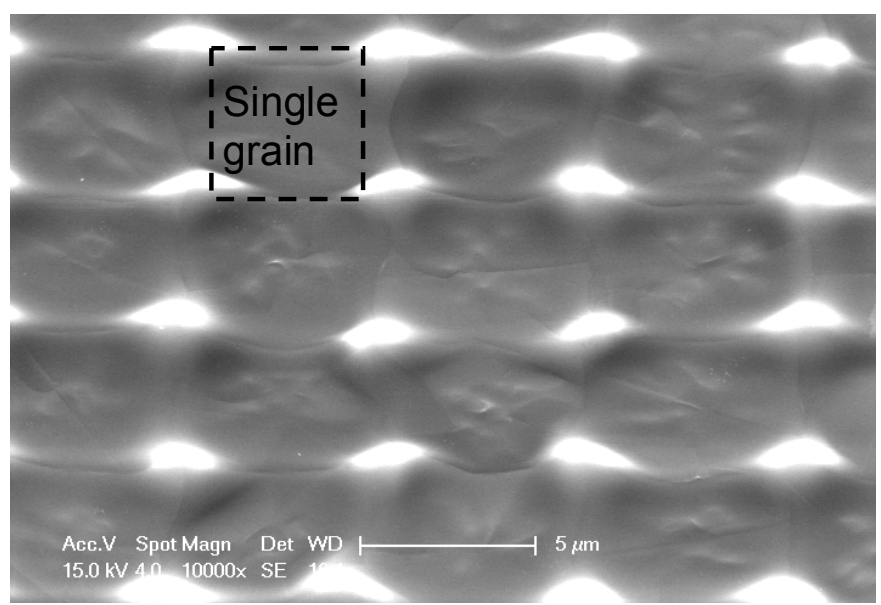

Figure 2. SEM picture of $6 \mu \mathrm{m} \times 6 \mu \mathrm{m}$ size grains in $1 \mu \mathrm{m}$ thick a-Si layer.

Channel region of the SG-TFTs and intrinsic region of the PIN PDs were designed to be located in each single grain, which is shown in Figure 3 (a) and (b), respectively, since at the grain boundaries there are dangling bonds which trap electrons limiting the carrier mobility. The sizes of the intrinsic region length $(\mathrm{L})$ are $1 \mu \mathrm{m}, 1.5 \mu \mathrm{m}$ and $2 \mu \mathrm{m}$. To increase the intrinsic area, the lateral PIN photodiodes were interdigitated as shown in Fig. 3 (b). We designed three different total intrinsic areas; $100 \mu \mathrm{m} \times 100 \mu \mathrm{m}, 250 \mu \mathrm{m} \times 250 \mu \mathrm{m}$ and $500 \mu \mathrm{m} \times 500 \mu \mathrm{m}$.

For TFTs, gate length and width were kept at $1.5 \mu \mathrm{m}$ microns and $4 \mu \mathrm{m}$ microns, respectively. SG- TFTs were fabricated in $250 \mathrm{~nm}$ thick crystallized silicon, while the PD arrays were fabricated using SOI (device thickness $=340 \mathrm{~nm}$ ), a-Si (thickness $=1 \mu \mathrm{m}$ ) and SG-Si (thickness $=1 \mu \mathrm{m}$ and $250 \mathrm{~nm}$ ) layers with $20 \mathrm{~mm} \times 20 \mathrm{~mm}$ die size. 
In Figure 4, optical image of crystallized silicon layer is shown. Upon laser irradiation to the a-Si layer, crystallization occurs from the grain filter locations forming location-controlled Si grains there whereas the outside crystallizes as micro-crystalline silicon as it fully melts. After crystallization of the a-Si, silicon islands were patterned by dry etching. Then $30 \mathrm{~nm}$ thick $\mathrm{SiO}_{2}$ was deposited by PECVD using TEOS at a temperature of $350{ }^{\circ} \mathrm{C} .675 \mu \mathrm{m}$ thick $\mathrm{Al}$ is deposited on the oxide and gate mask was used to pattern the deposited $\mathrm{Al}$ and oxide layers. Wafers were implanted with boron and phosphorous and dopants were activated by excimer-laser annealing at $25^{\circ} \mathrm{C}$. The patterned $\mathrm{Al}$ acts as a gate for the SG TFTs whereas, for the SG-PDs, it protects from the laser irradiation for the intrinsic region. The $\mathrm{Al}$ on top of the intrinsic region of the PDs was removed after the laser annealing. $800 \mathrm{~nm}$ PECVD-TEOS was deposited as a passivation layer. This layer is not etched from the intrinsic area of the photodiodes (Figure 5) in order to increase the light absorption by the anti-reflection. Fabricated dies were attached on test PCB via wirebonding, as shown in Figure 6.

Lateral PIN photodiodes, which enable the integration of TFTs on the same pixel, are employed to detect the visible light converted from X-ray by scintillator material. In photodiodes, photosensitive area must be large enough to detect sufficient light for high image quality. However, increasing depletion length in PN photodiodes results in low RC time constant. Therefore, PIN photodiodes are used to increase the photon detection. PIN photodiodes should be reversed biased where most of the voltage drops at the intrinsic area which results in a higher $\mathrm{S} / \mathrm{N}$ ratio. Hence, they should be used in high bandwidth applications.

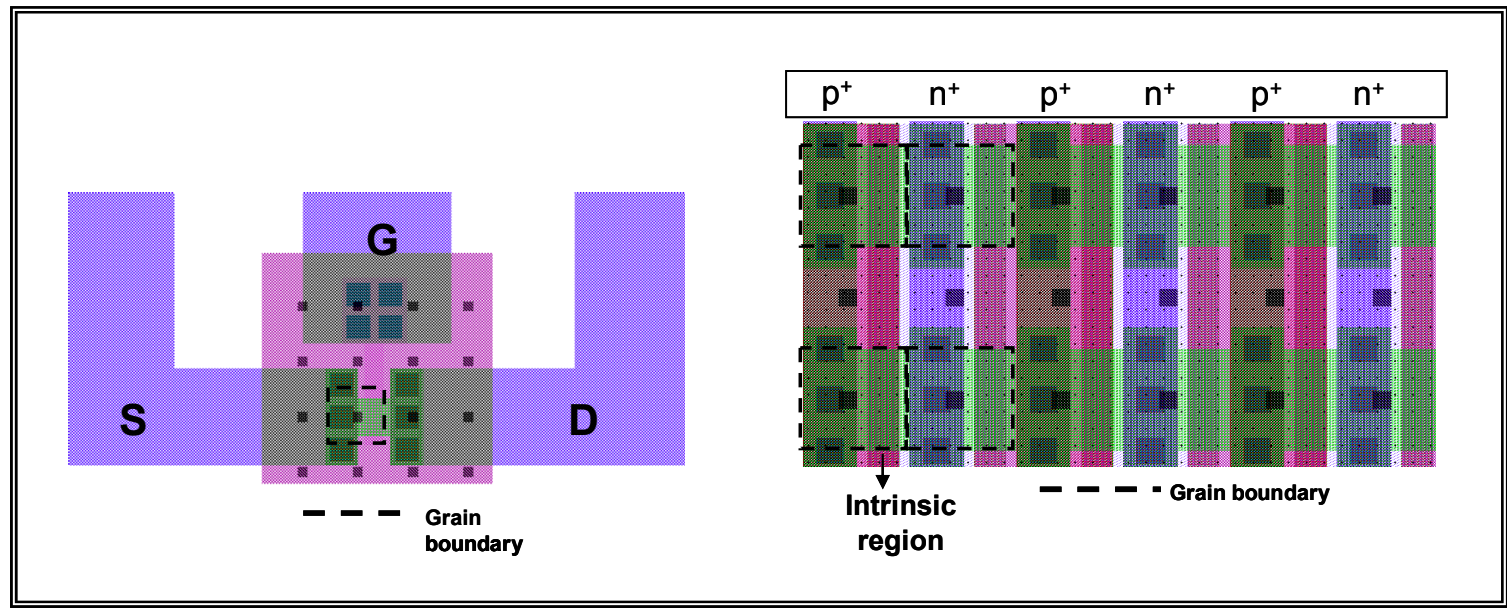

(a)

(b)

Figure 3. (a) SG- TFT and (b) SG- lateral PIN photodiode array designs.

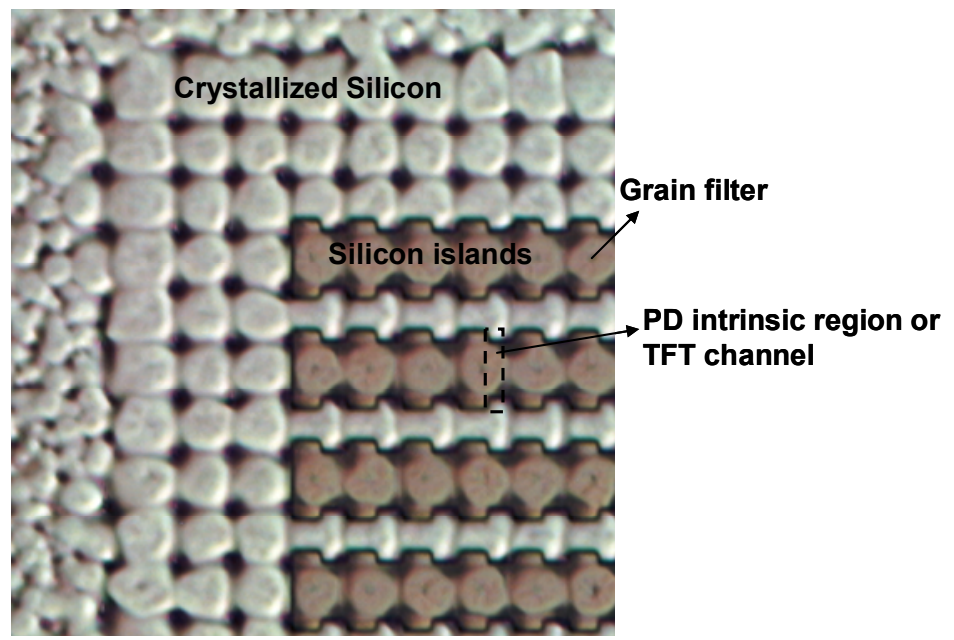

Figure 4. Optical image of crystallized silicon layer 


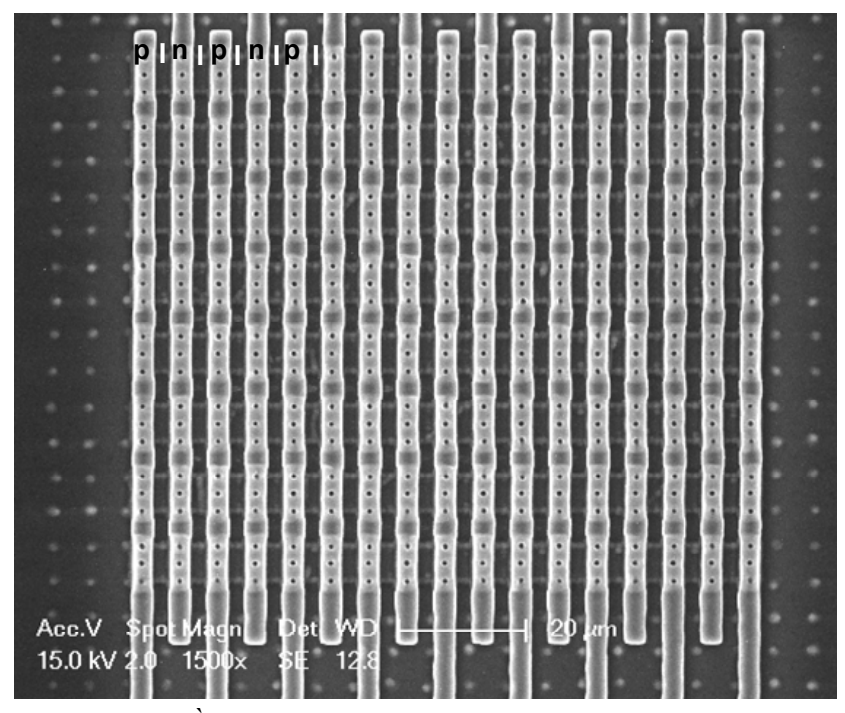

Figure 5. SEM picture of fabricated SG-lateral PIN photodiode in $1 \mu \mathrm{m}$ thick crystallized silicon layer.

\section{ELECTRICAL CHARACTERIZATION}

Electrical characteristics of the fabricated PD arrays and TFTs are illustrated in this section.

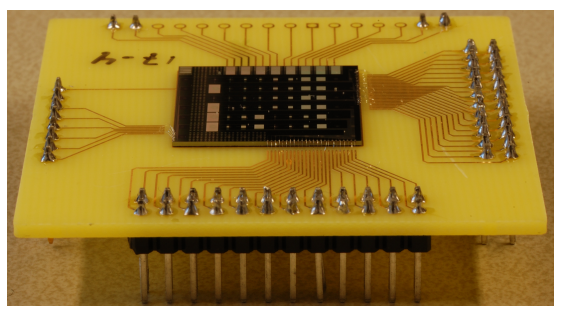

Figure 6. Picture of test chip.

\subsection{Electrical Measurements of Lateral SG- PIN Photodiodes}

In I-V measurements of the fabricated PD arrays, we used a white light source with $150 \mathrm{~W}$ powers. In Figure 7 , I-V curves of $100 \mu \mathrm{m} \times 100 \mu \mathrm{m}$ size and $1 \mu \mathrm{m}$ thick SG-PDs are compared with respect to different L values in illuminated $(\mathrm{ON})$ and dark states (OFF). Dark current and the saturation currents of the devices are on the order of $0.1 \mathrm{nA}$ and $10 \mathrm{nA}$ at $-2 \mathrm{~V}$, respectively, and those do not depend on the $\mathrm{L}$ value. Obtained sensitivity is about 200. Moreover, the ideality factor of the lateral PIN depends on L. While intrinsic area length increases, the I-V characteristic of SG-PDs deviates from ideal. As seen in the figure, increasing intrinsic area length results in photocurrent reduction at forward bias mode while the sensitivity stays same. 


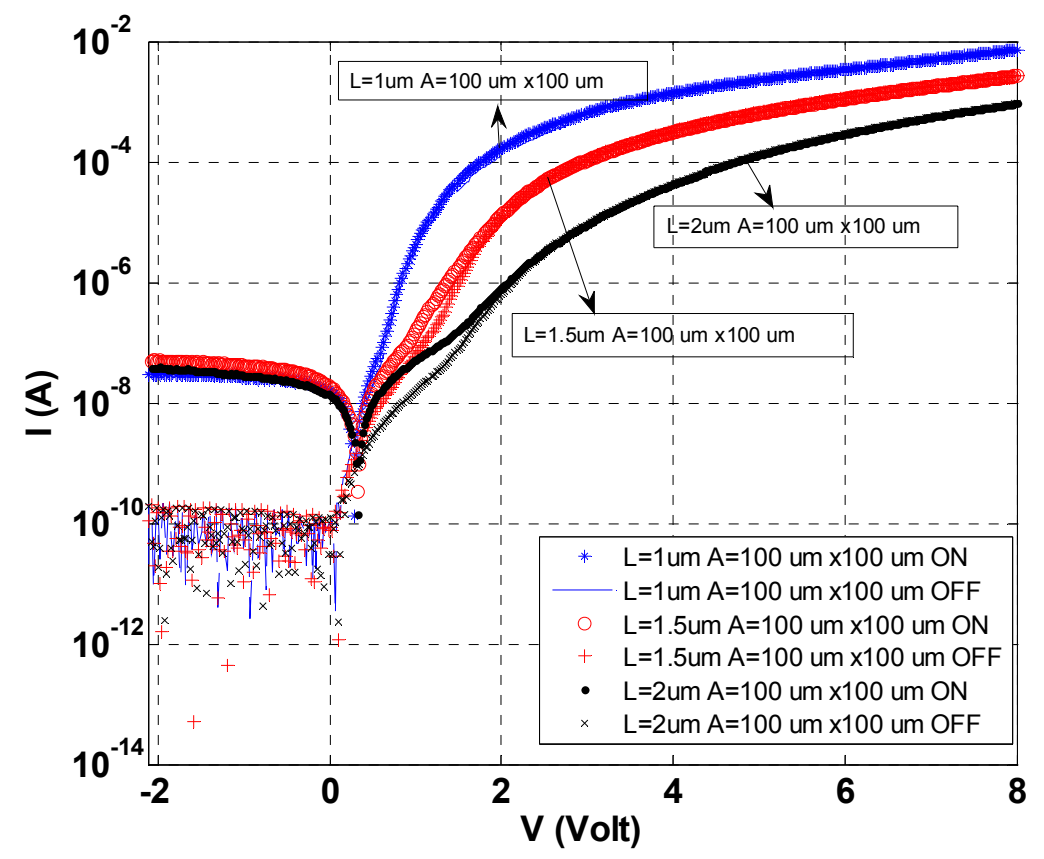

Figure 7. I-V curve comparison of $1 \mu \mathrm{m}$ thick SG-PDs. Sample intrinsic region sizes are: $1 \mu \mathrm{m}, 1.5 \mu \mathrm{m}$ and $2 \mu \mathrm{m}$. Sizes of the PD arrays are $100 \mu \mathrm{m}$ X $100 \mu \mathrm{m}$.

Dark state I-V curves of SG-photodiodes are compared in Figure 8. Sample array sizes are $100 \mu \mathrm{m} x 100 \mu \mathrm{m}, 250 \mu \mathrm{m} X$ $250 \mu \mathrm{m}$ and $500 \mu \mathrm{m} X 500 \mu \mathrm{m}$, while the intrinsic region length $\mathrm{L}$ was fixed at $2 \mu \mathrm{m}$. PD dark current in both forward and reverse increases with array size. This figure shows that, we are able to scale down the PD array size further, so that number of detector pixel can be increased.

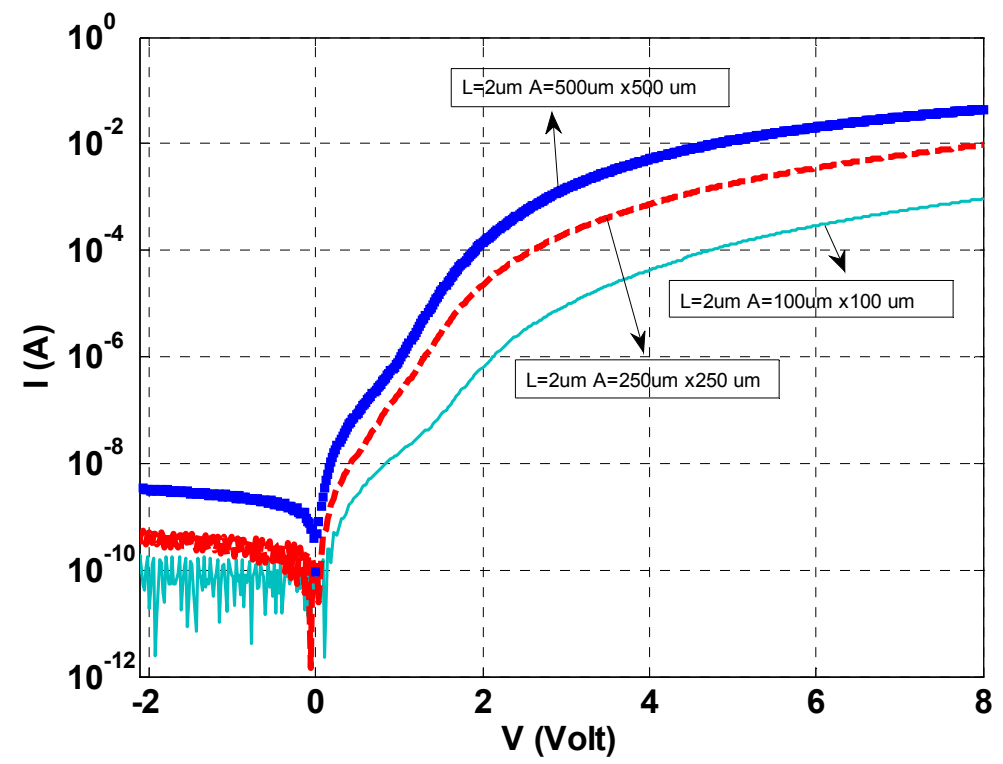

Figure 8. Dark current comparison of $1 \mu \mathrm{m}$ thick SG- PDs with respect to array size. Sample array sizes are: $100 \mu \mathrm{m} \mathrm{X} 100 \mu \mathrm{m}$, $250 \mu \mathrm{m} X 250 \mu \mathrm{m}$ and $500 \mu \mathrm{m}$ X $500 \mu \mathrm{m}$. Intrinsic region length is $2 \mu \mathrm{m}$. 
PD arrays were fabricated in c-Si (SOI wafer), a-Si and SG-Si layers. Thicknesses of c-Si and a-Si layers were $340 \mathrm{~nm}$ and $1 \mu \mathrm{m}$, respectively. In addition to $1 \mu \mathrm{m}$ thick SG-PDs, we also fabricated SG-PDs in $250 \mathrm{~nm}$ thick crystallized silicon layer in order to show its high electrical performance. Figure 9 shows I-V curves of those four diodes with $100 \mu \mathrm{m} \times 100$ $\mu \mathrm{m}$ array size and $1 \mu \mathrm{m}$ intrinsic region length. It shows that dark current under reverse bias is the same for those diodes. Photo-generated current of SOI- and SG-PDs $(1 \mu \mathrm{m}$ thick) are almost the same level, giving the light sensitivity of 260 and 230, respectively. Moreover, fabricated $1 \mu \mathrm{m}$ a-Si photodiodes have very low (less than 10) due to the dense defects. Fabricated SG and c-Si photodiodes reach higher photocurrent values than a-Si photodiodes at forward bias mode. In comparison to $1 \mu \mathrm{m}$ thick SG-PDs, the SOI-PDs reaches slightly higher photocurrent at forward bias due to slightly higher mobility. However, $250 \mathrm{~nm}$ thick SG-PDs have higher photocurrent than SOI-PDs with $340 \mathrm{~nm}$ c-Si layer.

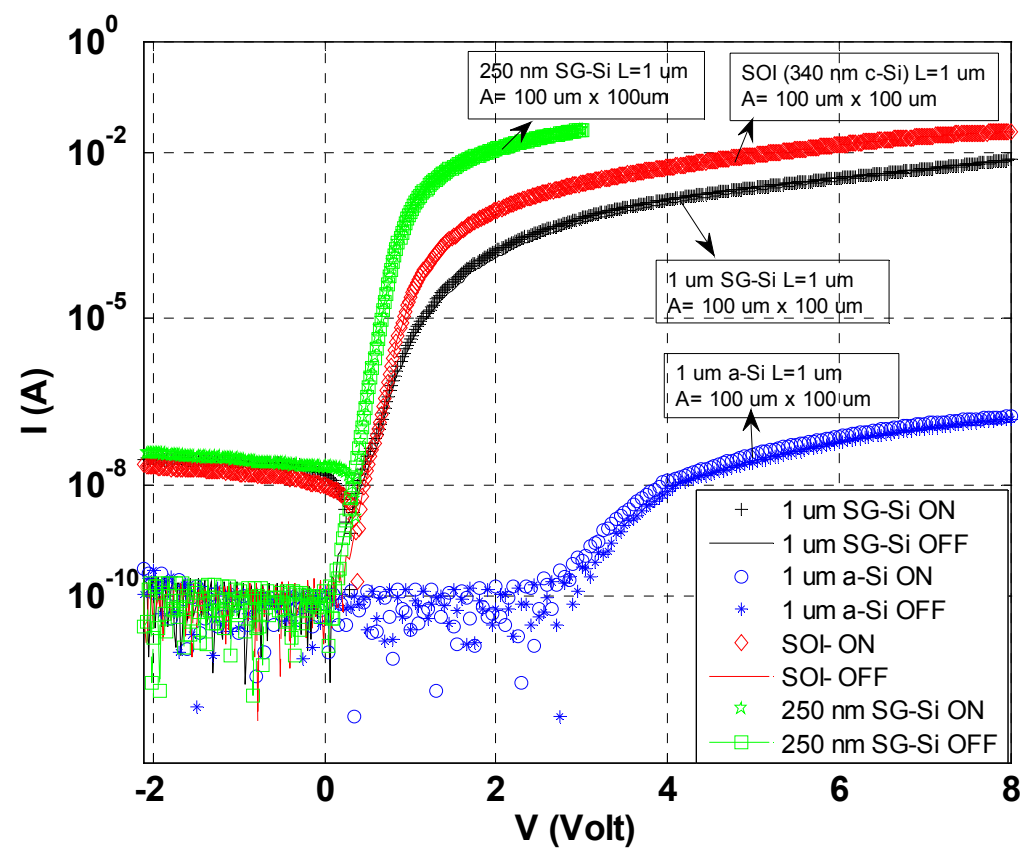

Figure 9. I-V curve comparison of PD arrays which fabricated in c-Si $(340 \mathrm{~nm})$, a-Si $(1 \mu \mathrm{m})$ and SG-Si $(250 \mathrm{~nm}$ and $1 \mu \mathrm{m})$ layers.

\subsection{Electrical Measurements of SG-TFT}

SG-TFTs were fabricated in $250 \mathrm{~nm}$ thick crystallized silicon layer. Id -Vg characteristics of SG-NMOS and PMOS TFTs are presented in Figure 10. Field effect mobility was derived from the linear region at $\mathrm{Vd}=200 \mathrm{mV}$ (drain voltage). Fabricated SG- NMOS and PMOS TFTs have mobility of $526 \mathrm{~cm}^{2} / \mathrm{Vs}$ and $253 \mathrm{~cm}^{2} / \mathrm{Vs}$, respectively. Mobility, subthreshold swing and threshold voltage values of the sample devices are shown in Table 1. Those values correspond well with our previous report [4]. 


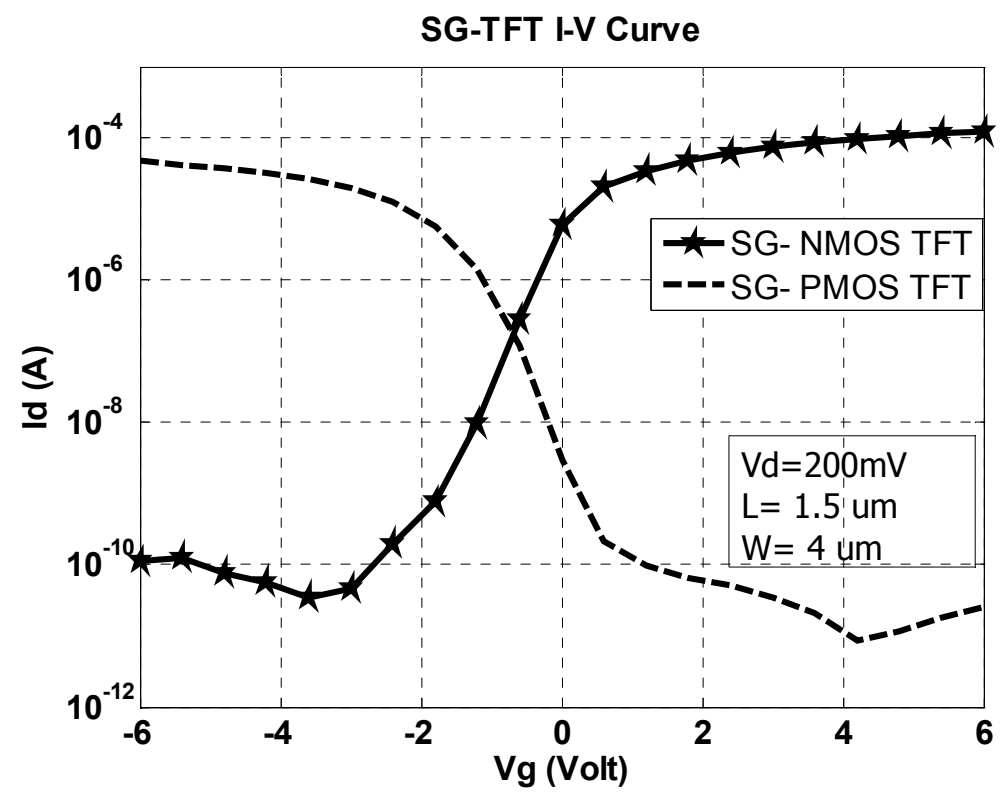

Figure 10. Id-Vg curve of fabricated SG-NMOS and PMOS TFTs in $250 \mu \mathrm{m}$ crystallized silicon layer. Drain voltage (Vd) is 200 $\mathrm{mV}$. Gate length and width are $1.5 \mu \mathrm{m}$ and $4 \mu \mathrm{m}$, respectively.

Table 1. : Measured mobility, subthreshold swing and threshold voltage values in average of the SOI- TFTs.

\begin{tabular}{|l|l|l|}
\hline & \multicolumn{1}{|c|}{ NMOS- TFT (L=1.5 um) } & \multicolumn{1}{|c|}{ PMOS- TFT (L=1.5 um) } \\
\hline Mobility $\left(\mathrm{cm}^{2} / \mathrm{Vs}\right)$ & 526 & 253 \\
\hline $\mathrm{V}_{\mathrm{th}}(\mathrm{V})$ & -0.3 & -0.5 \\
\hline $\mathrm{S}(\mathrm{V} / \mathrm{dec})$ & 0.4 & 0.37 \\
\hline
\end{tabular}

\section{CONCLUSION}

SG-photodiode arrays and SG-TFTs were designed and fabricated to develop a large area and low dose X-ray image sensor. Devices were fabricated in 2D-location controlled single grains. PD array size and intrinsic region length were varied and the electrical measurement results were presented. Dark current of $100 \mu \mathrm{m} \times 100 \mu \mathrm{m}$ size arrays are on the order of $0.1 \mathrm{nA}$ for SG- photodiodes with $1 \mu \mathrm{m}, 1.5 \mu \mathrm{m}$ and $2 \mu \mathrm{m}$ intrinsic region length and degrades in larger arrays. Mobility of the SG-NMOS and PMOS transistors are $526 \mathrm{~cm}^{2} / \mathrm{Vs}$ and $253 \mathrm{~cm}^{2} / \mathrm{Vs}$, respectively. Due to high mobility of SG-TFTs and high sensivity of SG-PDs, c-Si TFTs in X-ray image sensors can be substituted by crystallized silicon layer fabricated using location controlled $\mu$-Czochralski technique.

\section{Acknowledgments}

We would like to express sincere thanks to all DIMES clean room staff specially J. van der Cingel, M. van der Zwan in DIMES Technology Center and CATRENE (Cluster for Application and Technology Research in Europe on Nanoelectronics) for the support of this project. 


\section{REFERENCES}

[1] Kelly, A., Groves, G. W. and Kidd, P., [Crystallography and Crystal Defects], Wiley, New York, (2000).

[2] Moy, J. P., "Large area X-ray detectors based on amorphous silicon technology," Thin Solid Films 337, 213-221 (1999)

[3] Van der Wilt, P. C., Van Dijk, B. D., Bertens, G. J., Ishihara, R., and Beenakker, C. I. M., "Formation of locationcontrolled crystalline islands using substrate-embedded seeds in excimer-laser crystallization of silicon films," Applied Physics Letters, 79, 1819 (2001).

[4] Rana, V., Ishihara, R., Hiroshima, Y., Abe, D., Inoue, S., Shimoda, T., Metselaar, W. and Beenakker, K., "Dependence of Single-Crystalline Si TFT Characteristics on the Channel Position inside a Location-Controlled Grain," IEEE Transactions on Electron Devices, 52(12), 2622-2628 (2005) 